\title{
Imaging Evaluation of Plexiform Neurofibromas in Neurofibromatosis Type 1
}

\section{A Survey-Based Assessment}

\author{
Shivani Ahlawat, MD, K. Ina Ly, MD, Laura M. Fayad, MD, Michael J. Fisher, Andrés J. Lessing, MBA, \\ Dale J. Berg, BS, Johannes M. Salamon, MD, Victor-Felix Mautner, MD, Dusica Babovic-Vuksanovic, MD, \\ Eva Dombi, MD, Gordon Harris, PhD, Scott R. Plotkin, MD, PhD, and Jaishri Blakeley, MD, on behalf of the REiNS \\ International Collaboration
}

Neurology ${ }^{\circledR}$ 2021;97:S111-S119. doi:10.1212/WNL.0000000000012437

\section{Abstract \\ Objective}

To assess imaging utilization practices across clinical specialists in neurofibromatosis type 1 (NF1) for the evaluation of symptomatic and asymptomatic children and adults with or without plexiform neurofibromas (PN).

\section{Methods}

An institutional review board-exempt survey was administered to medical practitioners caring for individuals with NF1 at the Response Evaluation in Neurofibromatosis and Schwannomatosis (REiNS) meeting in September 2019. The survey included questions on respondent demographic data (9 questions), type of imaging obtained for asymptomatic (4 questions) and symptomatic (4 questions) people with and without $\mathrm{PN}$, and utilization of diffusion-weighted imaging ( 2 questions).

\section{Results}

Thirty practitioners participated in the survey. Most were academic neuro-oncologists at highvolume (>10 patients/week) NF1 centers. Of 30 respondents, 26 had access to whole-body MRI (WB-MRI). The most common approach to an asymptomatic person without PN was no imaging (adults: 57\% [17/30]; children: 50\% [15/30]), followed by a screening WB-MRI (adults: 20\% [6/30]; children: 26.7\% [8/30]). The most common approach to a person with symptoms or known PN was regional MRI (adults: 90\% [27/30]; children: 93\% [28/30]), followed by WB-MRI (adults: 20\% [6/30]; children: 36.7\% [11/30]). WB-MRI was most often obtained to evaluate a symptomatic child with PN (37\% [11/30]).

\section{Conclusions}

More than $90 \%$ of practitioners indicated they would obtain a regional MRI in a symptomatic patient without known or visible PN. Otherwise, there was little consensus on imaging practices. Given the high prevalence of $\mathrm{PN}$ and risk of malignant conversion in this patient population, there is a need to define imaging-based guidelines for optimal clinical care and the design of future clinical trials.

\author{
Correspondence \\ Dr. Ahlawat \\ sahlawa1@jhmi.edu
}




\section{Glossary}

ADC = apparent diffusion coefficient; DWI = diffusion-weighted imaging; MPNST = malignant peripheral nerve sheath tumor; NF1 = neurofibromatosis type 1; PN = plexiform neurofibroma; PNST = peripheral nerve sheath tumor; REiNS = Response Evaluation in Neurofibromatosis and Schwannomatosis; STIR = short tau inversion recovery; SUV = standard uptake value; WB-MRI = whole-body MRI.

Plexiform neurofibroma (PN) affect 30\%-60\% of individuals with neurofibromatosis type 1 (NF1), ${ }^{1-3}$ can cause significant disability, and $8 \%-13 \%$ undergo transformation into malignant peripheral nerve sheath tumors (MPNSTs).$^{2-7}$ Although radiology plays an important role in managing individuals with NF1, there are limited data and many unanswered questions regarding the optimal imaging strategy for evaluating symptomatic and asymptomatic peripheral nerve sheath tumors (PNSTs): (1) Is regional MRI or whole-body MRI (WB-MRI) better for the characterization and surveillance of known PN? (2) Is WB-MRI a more sensitive approach to physical examination with regional MRI for screening to detect asymptomatic PN? (3) What are the best surveillance intervals for a known PN or screening methods for PN/ MPNST? (4) What are the best uses of WB-MRI, such as screening for $\mathrm{PN}$ in children to monitor for PN-related morbidity or screening for whole-body PN tumor burden as a patient enters adulthood to predict lifetime MPNST risk ${ }^{4}$ ?

To understand expert clinicians' approaches to evaluating symptomatic and asymptomatic people with NF1 and PNSTs, we administered a survey to medical practitioners caring for patients with NF1 in designated specialty centers. We hypothesized that the lack of evidence-based guidelines would lead to heterogeneous application of imaging for both diagnosis and surveillance of NF1-associated PNSTs. Ultimately, standardizing the approach to imaging of patients is desirable to improve the value and accuracy of clinical care and to identify patients most appropriate for clinical trials.

\section{Methods}

\section{Overview}

The Response Evaluation in Neurofibromatosis and Schwannomatosis (REiNS) Imaging Working Group designed a survey (JHMI protocol IRB00142837) consisting of 19 questions on demographic data of respondents (9 questions), imaging practices for an asymptomatic adult or child with NF1 with and without known PN (4 questions), imaging practices for a symptomatic adult or child with NF1 with and without known PN (4 questions), and utilization of diffusion-weighted imaging (DWI; 2 questions). Adults and children were defined as $\geq 18$ and $<18$ years of age, respectively.

\section{Standard Protocol Approvals, Registrations, and Patient Consents}

This survey was deemed institutional review board exempt (JHMI protocol IRB00142837).

\section{Survey Questions}

\section{Demographic Data}

Only respondents who provide clinical care for people with NF1 in their clinical practice were included in the analysis. We gathered information on the scope of the respondents' clinical practice, type of clinical practice (academic, private, hybrid, government, or other), medical specialty, pediatric or adult focus, geographic location, duration of experience, and number of patients seen in a typical work week.

\section{Imaging Practices for an Asymptomatic Adult or Child With NF1 With and Without PN}

Survey respondents were asked about the type of imaging they used for baseline assessment of an asymptomatic child or adult (WB-MRI, ${ }^{18}$ F-FDG PET/CT), no imaging, or other with the option to provide a free-text answer) as well as type of follow-up imaging and time interval for follow-up if follow-up imaging was obtained.

\section{Imaging Practices for a Symptomatic Adult or Child With NF1 With and Without PN}

Survey respondents were asked about the type of imaging they used for baseline assessment of a symptomatic child or adult (regional MRI of the symptomatic body region, WBMRI, ${ }^{18}$ F-FDG PET/CT, no imaging, or other with the option to provide a free-text answer) as well as type of follow-up imaging and time interval for follow-up if followup imaging was obtained.

\section{Utilization of Quantitative Imaging Markers}

Survey respondents were asked whether they used DWI and apparent diffusion coefficient (ADC) values and which imaging features were most helpful in triaging a patient to biopsy for suspected MPNST (change in tumor size, low ADC values on MRI, elevated standard uptake values [SUVs] on ${ }^{18} \mathrm{~F}$-FDG $\mathrm{PET} / \mathrm{CT}, \mathrm{SUV}>$ ADC $>$ size, $\mathrm{ADC}>\mathrm{SUV}>$ size, all of the above, and none of above).

\section{Statistical Analysis}

Comparisons were tested for significance using $\chi^{2}$ tests for categorical variables and independent $t$ tests for continuous variables.

\section{Data Availability}

Anonymized data will be shared by request with qualified investigators. 


\section{Results}

\section{Demographic Data}

Thirty clinical experts participated in the survey. Most respondents practiced at academic centers $(27 / 30 ; 90 \%)$ and were neuro-oncologists $(14 / 30 ; 47 \%)$ in the United States $(27 / 30 ; 90 \%)$. One third of respondents $(10 / 30)$ worked in high-volume clinics treating $>10$ patients with NF1 per week. In addition to neuro-oncologists, other practitioners reported their specialty as radiology $(n=1)$, pediatrics $(n=2)$, medical genetics $(n=3)$, hematology-oncology $(n=4)$, and neurology $(n=5)$. Aside from the United States, Europe $(n=2)$ and Australia $(\mathrm{n}=1)$ were identified as the other geographic locations. The majority $(26 / 30 ; 87 \%)$ of the survey respondents had access to WB-MRI at their institution (figure 1).

\section{Imaging Practices for an Asymptomatic Adult or Child With NF1 With and Without PN}

In an asymptomatic patient without a PN, 50\%-57\% (15/30 for children, $17 / 30$ for adults) of respondents indicated they do not routinely obtain imaging; $20 \%-27 \%$ (6/30 for adults, $8 / 30$ for children) obtain WB-MRI. In an asymptomatic patient with a visible or known PN, 60\% (18/30 for children and adults) of respondents indicated they obtain a regional MRI; $20 \%-27 \%$ (6/30 for adults, $8 / 30$ for children) obtain WB-MRI (figure 2). Only 1 respondent each opted for whole-body ${ }^{18}$ F-FDG PET/
CT or whole-body ${ }^{18}$ F-FDG PET/MRI when evaluating an asymptomatic individual with NF1, irrespective of age group or whether they had a known or visible PN. One survey respondent without access to WB-MRI indicated utilization of a whole-spine and short tau inversion recovery (STIR) sequence of the body. No respondent indicated obtaining regional MRI or brain MRI in an asymptomatic person with NF1 with or without PN.

\section{Use of WB-MRI in Asymptomatic Adults and Children With or Without PN}

In asymptomatic adults, the proportion utilizing WB-MRI (20\% [6/30]) did not change based on the presence or absence of PN. Similarly, in asymptomatic children, the WB-MRI utilization proportion (26.7\% [8/30]) did not change based on the presence or absence of PN. There was no statistical difference in the survey respondents' utilization of WB-MRI in asymptomatic pediatric vs adult patients $(26.7 \%[8 / 30]$ vs $20 \%[6 / 30], p=0.76)$. In the minority of the practitioners who order WB-MRI, a follow-up WB-MRI would be obtained annually, irrespective of whether patients did or did not have a known or visible PN (table).

\section{Surveillance Patterns for Asymptomatic Patients With NF1}

In patients with a known or visible $\mathrm{PN}$, the imaging interval was more variable $(0.5-3$ years for regional MRI and 1-2 years for WB-MRI). Two survey respondents (7\%) reported

Figure 1 Demographic Data of Survey Respondents

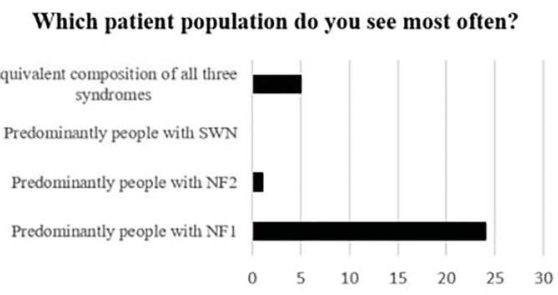

What best describes your clinical practice?

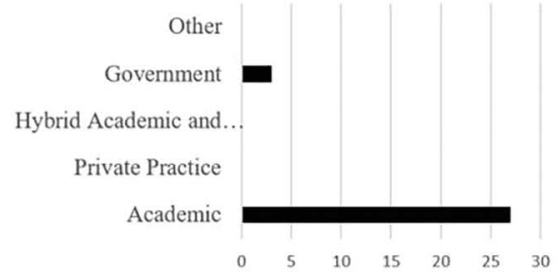

What best describes your field of expertise?

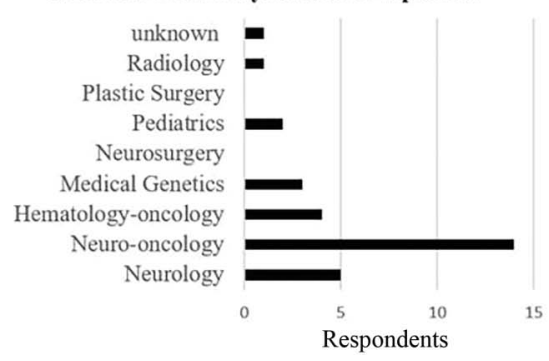

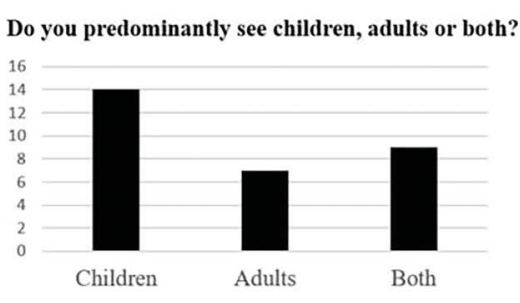

Where are you located?

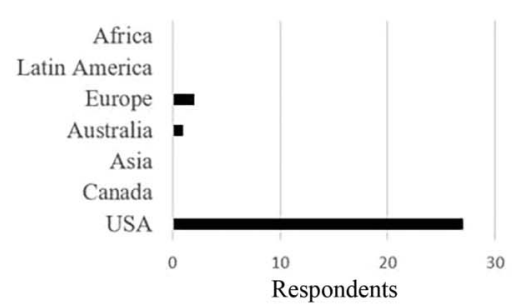

How long have you focused on NF1 clinical care?

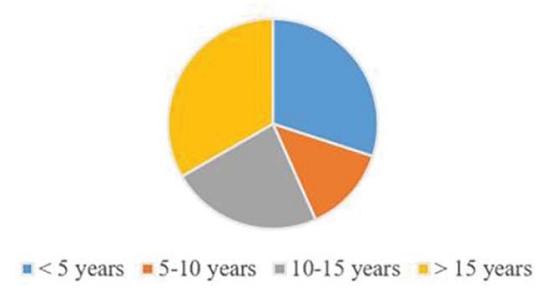

How many people with NF1 do you see in a typical work week?

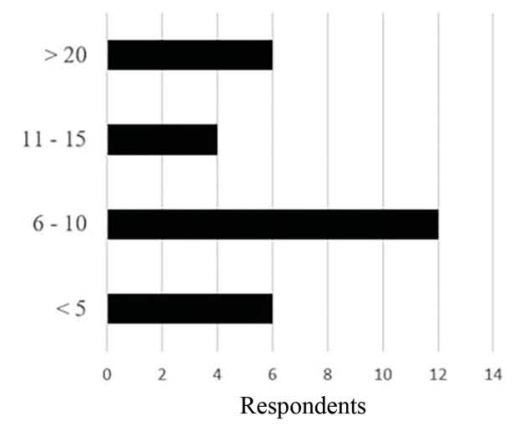

Do you have access to whole body MRI?

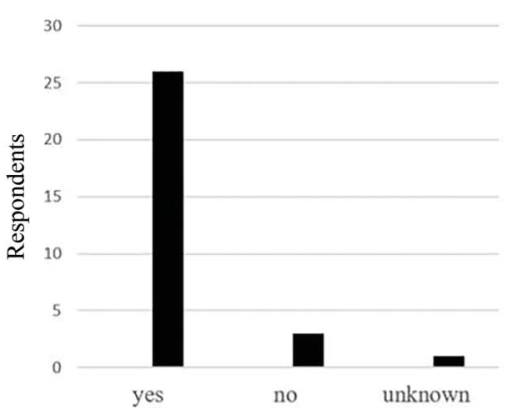

Most respondents were academic neuro-oncologists practicing in the United States in high-volume clinics treating $>10$ patients with neurofibromatosis type 1 (NF1) per week. NF2 = neurofibromatosis type 2; SWN = schwannomatosis. 
Figure 2 Imaging Utilization in Asymptomatic People With Neurofibromatosis Type 1 (NF1) With or Without Known Plexiform Neurofibroma (PN)

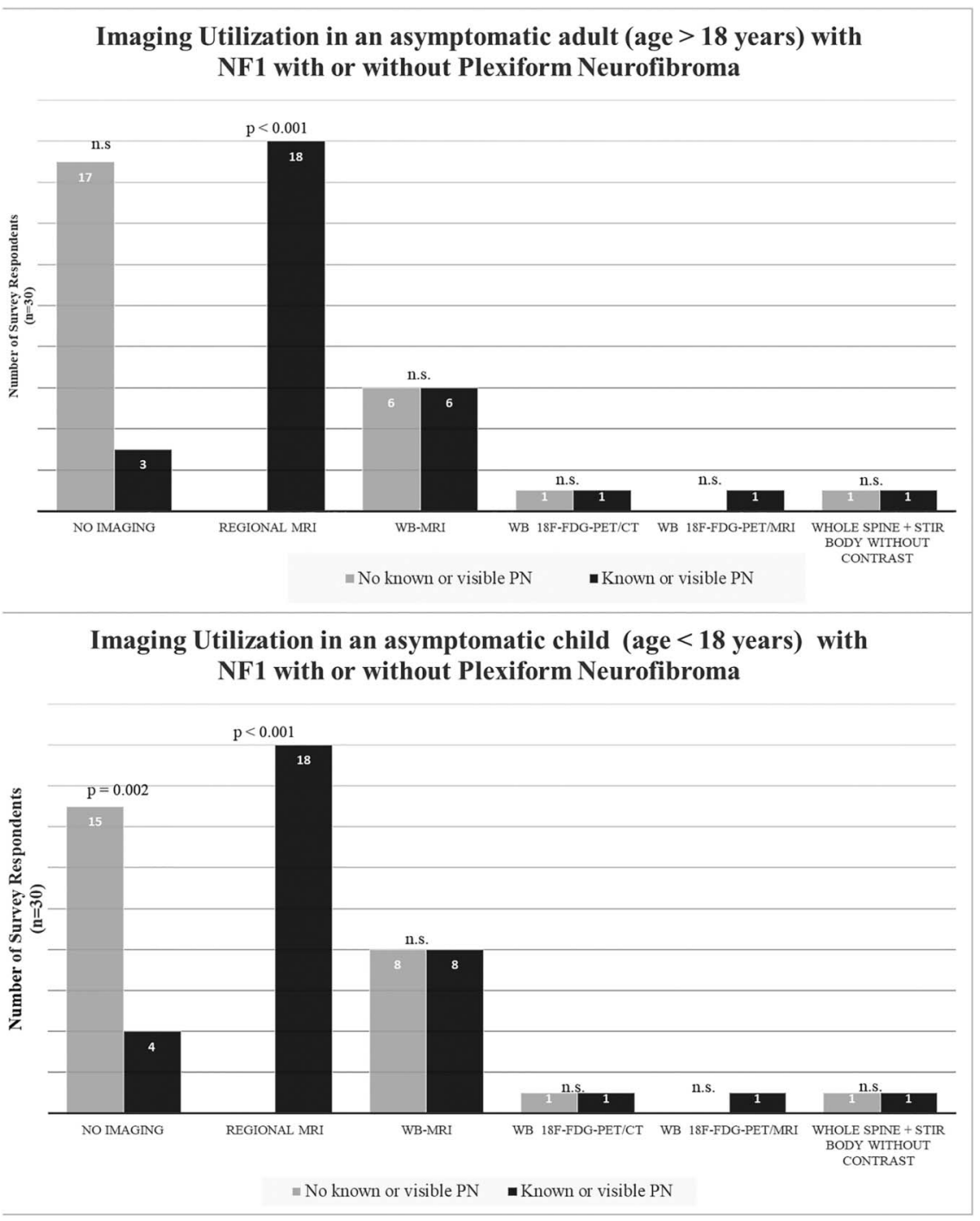

In an asymptomatic patient without a visible or known PN, $50 \%-57 \%$ of respondents indicated they do not routinely obtain imaging; $60 \%$ of respondents indicated they obtain a regional MRI. n.s. = not significant; STIR = short tau inversion recovery; WB-MRI = whole-body MRI. use of whole-body ${ }^{18}$ F-FDG PET/CT and whole-body ${ }^{18} \mathrm{~F}$ FDG PET/MRI for surveillance of children at 1- to 2-year intervals. The table shows the follow-up imaging intervals and preferences of imaging modalities for asymptomatic adults or children with NF1 with and without PN. Survey respondents provided variable imaging interval strategies with WB-MRI being used in asymptomatic adults annually with a greater variability in children (interval: 1-3 years). In the setting of a known or visible $\mathrm{PN}$, the imaging interval was minimally shorter (range 0.5-3 years for regional MRI and 1-2 years for WB-MRI). Two survey respondents $(7 \%)$ reported use of whole-body ${ }^{18}$ F-FDG PET/ CT and whole-body ${ }^{18}$ F-FDG PET/MRI as their method of surveillance in asymptomatic children at 1- to 2-year intervals.

\section{Imaging Practices for a Symptomatic Adult or Child With NF1 With and Without PN}

In a symptomatic patient without a visible or known PN, $\geq 90 \%$ (27/30 for adults, $28 / 30$ for children) of respondents indicated use of regional MRI. The number was slightly lower if a symptomatic patient was known to have a PN (80\%-87\% [24/30 for adults, 26/30 for children] of respondents). WB-MRI was the second most common imaging modality obtained in a symptomatic patient $(27 \%-37 \%$ of respondents, depending on age of the patient and whether patients had a visible or known PN) (figure 3). WB-MRI was most often obtained in the setting of a symptomatic child with known or visible PN (36.7\% [11/30]). A very small subset opted for whole-body ${ }^{18} \mathrm{~F}$-FDG PET/CT in the absence of PN (3.3\% [1/30] for adults and 10\% [3/30] for children). However, the number of survey respondents using wholebody ${ }^{18}$ F-FDG PET/CT for the evaluation of a symptomatic child with $\mathrm{PN}$ was somewhat higher compared with adults, although this was not statistically significant $(3.3 \%[1 / 30]$ for adults and $16.7 \%$ $[5 / 30]$ for children, $p=0.37)$. A small subset $(3.3 \%-6.7 \%)$ opted for whole-body ${ }^{18}$ F-FDG PET/MRI ( $1 / 30$ for adults and children without $\mathrm{PN}$ and 2/30 for adults and children with $\mathrm{PN}$ ). 
Table Follow-Up Imaging Interval in People With Neurofibromatosis Type 1 (NF1)

\begin{tabular}{|c|c|c|c|c|}
\hline & \multicolumn{2}{|c|}{ Asymptomatic adult (age $>18$ years) } & \multicolumn{2}{|c|}{ Symptomatic adult (age $>18$ years) } \\
\hline & No known or visible PN & Known or visible PN & No known or visible PN & Known or visible $\mathrm{PN}$ \\
\hline Regional MRI & 0 & $1-2$ y (range $0.5-3)$ & 1 y (range $0.25-3)$ & 1 y (range $0.5-5)$ \\
\hline WB-MRI & $1 \mathrm{y}$ & 1 y (range $1-2)$ & 1 y (range $1-2)$ & 1 y (range $0.5-2)$ \\
\hline Whole-body ${ }^{18}$ F-FDG PET/CT & 0 & $1 \mathrm{y}$ & $1-2 y$ & $1 \mathrm{y}$ \\
\hline \multirow[t]{3}{*}{ Whole-body ${ }^{18} \mathrm{~F}$-FDG PET/MRI } & 0 & 0 & $2 y$ & $0.5-2 y$ \\
\hline & \multicolumn{2}{|c|}{ Asymptomatic child (age $<18$ years) } & \multicolumn{2}{|c|}{ Symptomatic child (age <18 years) } \\
\hline & No known or visible PN & Known or visible PN & No known or visible PN & Known or visible PN \\
\hline Regional MRI & 0 & $1-2$ y (range $0.5-3)$ & 1 y (range $0.25-3)$ & 1 y (range $0.5-5)$ \\
\hline WB-MRI & 1 y (range $1-3)$ & 1 y (range $1-2)$ & $1 \mathrm{y}$ & 1 y (range $0.5-2)$ \\
\hline Whole-body ${ }^{18} \mathrm{~F}$-FDG PET/CT & 0 & $1 \mathrm{y}$ & $1 \mathrm{y}$ & 1 y (range $1-3)$ \\
\hline Whole-body ${ }^{18} \mathrm{~F}$-FDG PET/MRI & 0 & $1-2 y$ & $2 y$ & $0.5-2 y$ \\
\hline
\end{tabular}

Abbreviations: $\mathrm{PN}=$ plexiform neurofibroma; $\mathrm{WB}-\mathrm{MRI}=$ whole-body $\mathrm{MRI}$.

\section{Surveillance Patterns for Symptomatic Patients With NF1}

Survey respondents reported a wide range of follow-up imaging frequency for regional MRI (table). Intervals ranged from 3 to 6 months to 2 years in adults and children with or without visible PN. Respondents indicated the use of WBMRI on an annual basis in the absence of $\mathrm{PN}$ in adults and children; however, the surveillance interval ranged from 6 months to 2 years in the presence of a PN. One survey respondent opted to use whole-body ${ }^{18}$ F-FDG PET/CT and one reported the use of whole-body ${ }^{18} \mathrm{~F}$-FDG PET/MRI as a surveillance method performed at an interval of 2 years in the absence of a PN and 6 months-2 years in the presence of known or visible PN.

\section{Utilization of Quantitative Imaging Markers}

Most survey respondents $(26 / 30$ [86\%]) reported the use of DWI and ADC in their imaging practice but only $10 \%(3 / 30)$ identified $\mathrm{ADC}$ values as the most helpful imaging marker to triage a patient to a diagnostic biopsy. Instead, $50 \%$ of respondents $(15 / 30)$ reported SUV values from whole-body ${ }^{18}$ F-FDG PET-CT imaging to be most valuable for selecting patients for biopsy (figure 4).

\section{Discussion}

A survey-based questionnaire administered to medical practitioners providing care for individuals with NF1 who attended the REiNS meeting at the Children's Tumor Foundation annual NF Conference in September 2019 revealed a wide range of imaging utilization for adults and children with NF1. Lack of evidence-based guidelines on the role of imaging in the management of patients with NF1 leads to an overall heterogeneous application of imaging for both diagnosis and surveillance of NF1-associated PNSTs, making both clinical care and enrollment to clinical trials challenging for this patient population. More than $90 \%$ of practitioners indicated they would obtain a regional MRI in a symptomatic patient without a known or visible tumor. Aside from this, there was little consensus on imaging practices.

Regarding screening, approximately $50 \%$ of practitioners would not obtain baseline/screening imaging if the patient did not have symptoms or a known PN. This is interesting as there are multiple studies showing that up to $60 \%$ of patients with NF1 have internal or deep PN. ${ }^{10}$ While these may be asymptomatic initially, some patients are at higher risk of tumor growth and development of morbidity. ${ }^{11}$ In addition, with emerging therapies for $\mathrm{PN}$, consideration is being given to screening of children to evaluate for PN at high risk for morbidity, understanding the natural history of $\mathrm{PN}$, and being able to distinguish high-risk from low-risk $\mathrm{PN}$ for progression and transformation. However, in the absence of data there is not yet consensus about which individual with NF1 should have baseline screening imaging and with what modality.

Regarding the question of imaging modality for screening, given data suggesting that total body tumor burden is associated with increased likelihood of adult-onset MPNST, ${ }^{3}$ many have advocated WB-MRI screening of patients as they enter adulthood. ${ }^{2}$ WB-MRI can capture whole-body tumor burden in a single imaging session and delineate tumors that cross anatomical planes that may not be captured by a single regional MRI. ${ }^{8,9}$ In addition, acquisition measures, imaging sequences, and anatomical coverage and orientation often vary over time with regional MRIs, which can make it challenging to perform accurate scan-to-scan comparisons of PN. As such, WB-MRI is an ideal method to perform extent-ofdisease evaluations for PN in NF1. That said, the survey 
Figure 3 Imaging Utilization in Symptomatic People With Neurofibromatosis Type 1 (NF1) With or Without Known Plexiform Neurofibroma (PN)

Imaging Utilization in a symptomatic adult (age $>18$ years) with NF1 with or without Plexiform Neurofibroma

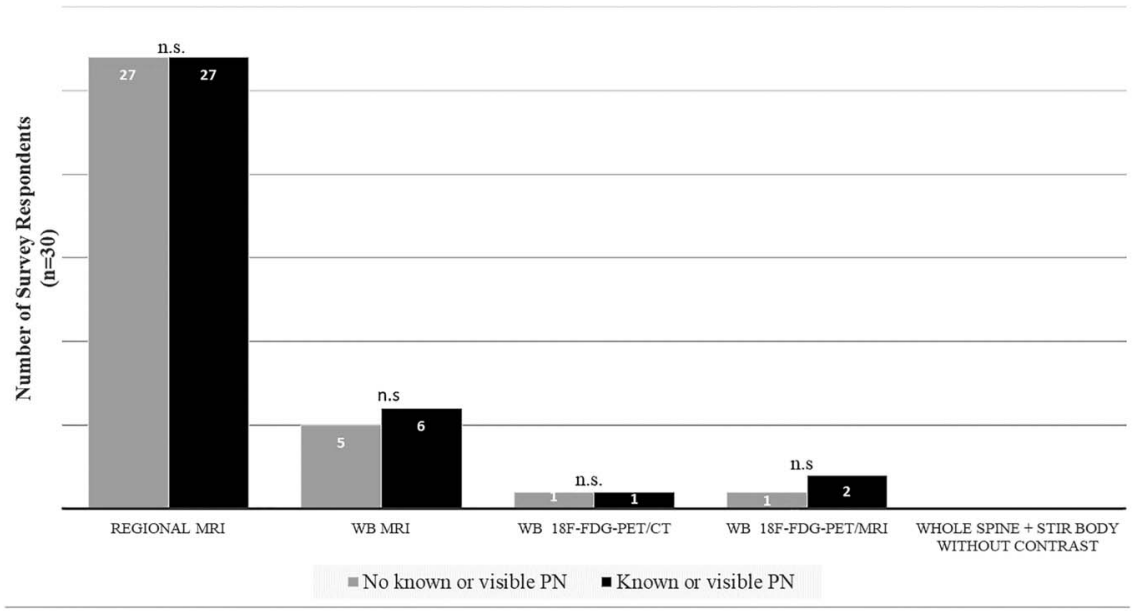

Imaging Utilization in a symptomatic child (age $<18$ years) with NF1 with or without Plexiform Neurofibroma

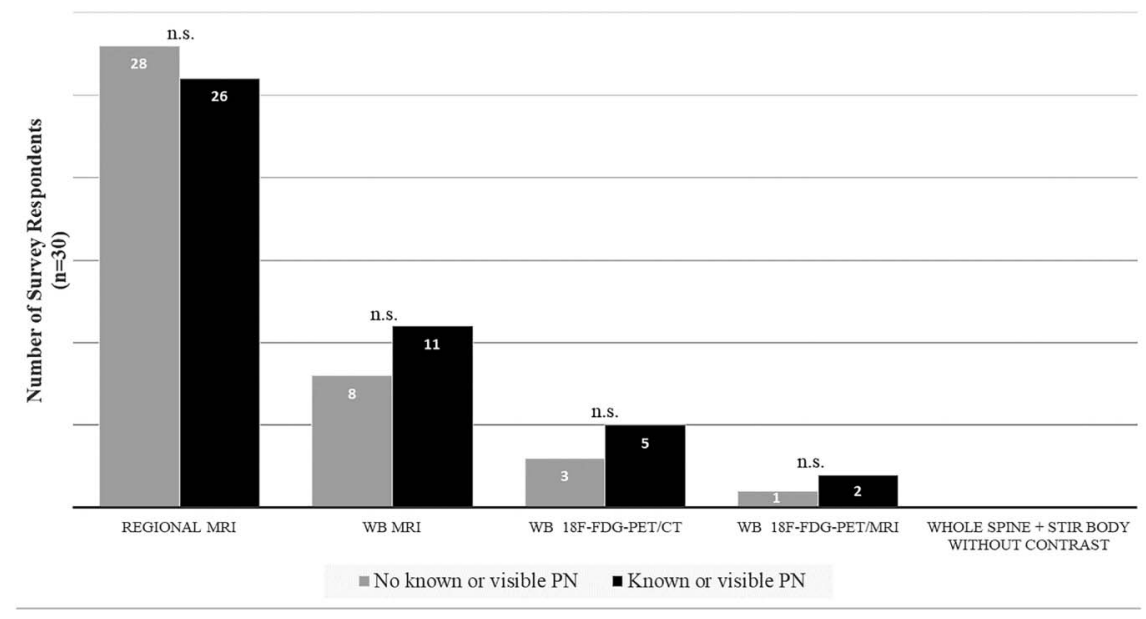

In a symptomatic pediatric or adult patient without a visible or known PN, $\geq 90 \%$ of respondents indicated preferential use of a regional MRI. n.S. = not significant; STIR = short tau inversion recovery; WB-MRI = whole-body MRI.

practitioners reported using physical examination with regional MRI based on examination findings for screening both children and adults for PN, with only $20 \%-27 \%$ of practitioners stating they obtain WB-MRI in people with NF1 with and without a known PN at any age. This may be because of the lack of explicit evidence supporting WB-MRI as a screening strategy to reduce NF1-related morbidity and mortality. Those who routinely screen with WB-MRI reference its usefulness in guiding long-term surveillance plans, sharing prognosis for future morbidity related to $\mathrm{PN}$, and selection for treatment based on PN burden. ${ }^{12}$

For adults with known PN, most practitioners indicated that they would choose a regional MRI over a WB-MRI as the firstline imaging modality. It is unlikely that lack of availability of WB-MRI would explain this given that almost 90\% (26/30) of respondents reported they had access to this technology. Rather, the ability to obtain high-resolution images with minimal scan time, particularly for tumors that do not cross body boundaries, as well as the use of regional MRI as the gold standard for response assessment on PN clinical trials likely contribute to this. We further speculate that other factors contribute to the relatively lower utilization rate of WB-MRI, including low approval rates of WB-MRI by insurance companies and lack of prospective data about performance and values of WB-MRI beyond expert recommendations. In addition, some ordering providers may perceive WB-MRI to be more time-consuming and technically more complicated than a regional MRI. Interestingly, WB-MRI was most often obtained in the setting of a symptomatic child with known or visible PN (36.7\% [11/30]) rather than as a screening tool in asymptomatic children without known or visible PN. We hypothesize that the tendency of PN to cross traditional anatomic planes and the excellent coverage afforded by WBMRI play a role in the selection of WB-MRI over regional MRI in this patient population. Robust prospective data 

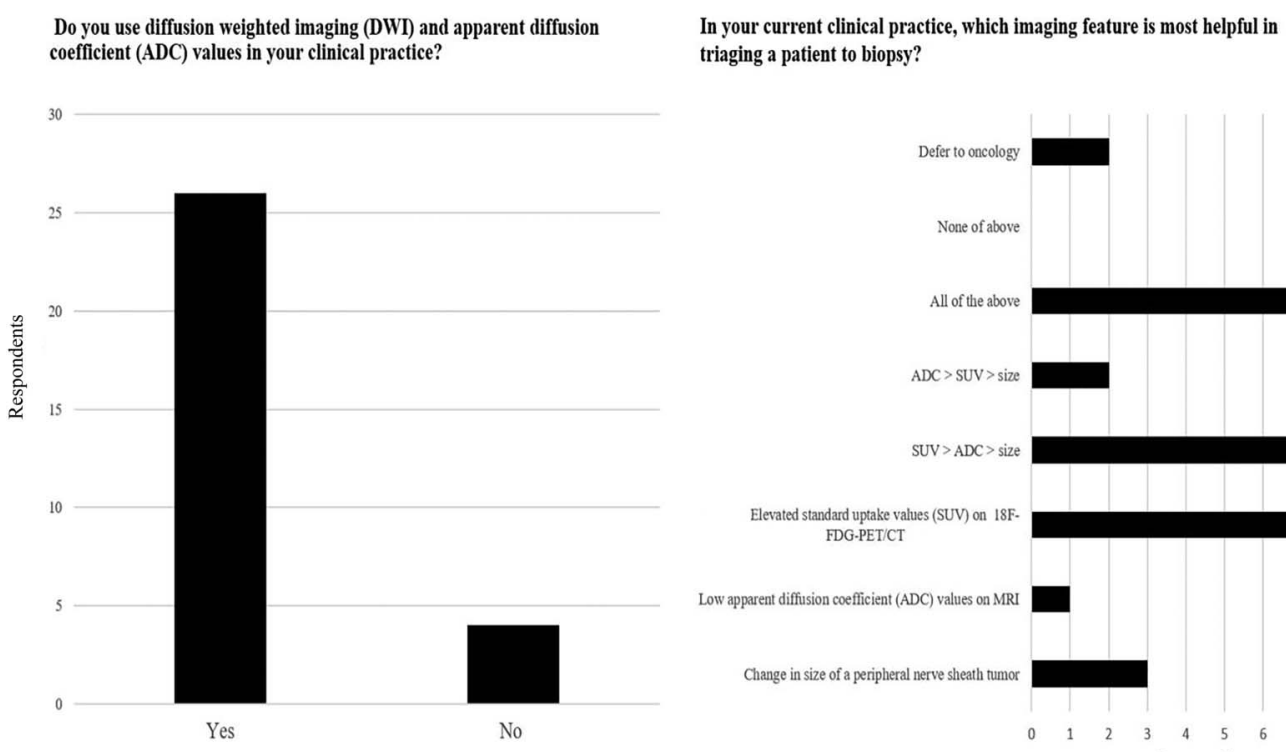

triaging a patient to biopsy?

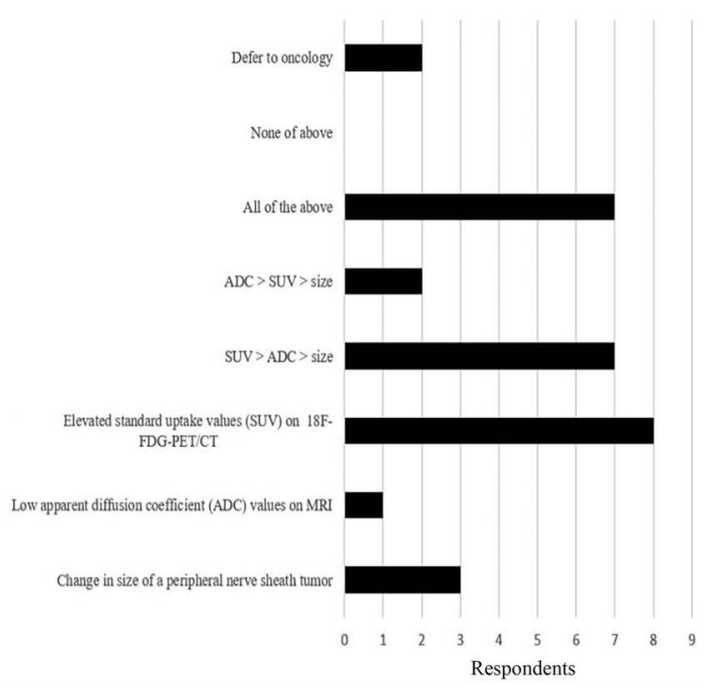

Although most survey respondents (26/30 [86\%]) reported the use of diffusion-weighted imaging (DWI) and apparent diffusion coefficient (ADC) in their imaging practice, $50 \%$ of the survey respondents (15/30) reported SUV values from whole-body ${ }^{18} \mathrm{~F}$-FDG PET-CT imaging to be most valuable for selecting patients for a biopsy.

supporting the advantages of WB-MRIs are needed to confirm its value, overcome potential insurance-related hurdles, and increase awareness of optimal uses of this modality.

There are no consensus guidelines on the use of MRI (regional or whole-body) for the diagnosis and surveillance of PNST in individuals with NF1. Standardized recommendations would be useful for several reasons. Firstly, this information is critical to identify individuals who would benefit from treatment of PN or would be eligible for clinical trials. For example, people with NF1 who are asymptomatic and without PN may not require surveillance, while those with PN may benefit from regional or WB-MRI surveillance. Secondly, presence or absence of deep or internal $\mathrm{PN}$ in a person with NF1, even if asymptomatic, may serve as a predictive biomarker for future development of MPNST. ${ }^{10}$ In addition, baseline imaging of PN offers a method for documenting growth that represents a risk for both morbidity ${ }^{13}$ and MPNST development. ${ }^{4}$ Baseline and surveillance imaging can also detect distinct nodular lesions or atypical neurofibromas arising in the background of $\mathrm{PN},{ }^{14}$ which have been identified as possible precursor lesions for malignancy. ${ }^{15}$ Lastly, there are novel therapeutic interventions such as MEK inhibitors and clinical trials that can be considered for the treatment of PN. In a phase I/II trial of pediatric patients with NF1 with inoperable PN treated with the MEK inhibitor selumetinib, $71 \%$ of patients experienced significant tumor shrinkage (defined as a decrease in tumor volume by $\geq 20 \%$ on imaging). ${ }^{16}$ Selumetinib was approved in April 2020 for treatment of patients with NF1 by the US Food and Drug Administration. As selumetinib enters regular clinical use, baseline and surveillance imaging is increasingly important to select the patient population most appropriate for treatment.

Regarding time interval of imaging, there was tremendous variability across practitioners. For asymptomatic adults and children, the typical surveillance interval was 1 year (range 0.5-3 years). Similarly, for symptomatic adults and children, the typical surveillance interval was 1 year (range $0.5-5$ years) with the shortest interval reported for a symptomatic child without a known or visible $\mathrm{PN}$ and longest interval for symptomatic adult with a visible or known PN. The lack of data for or against specific surveillance strategies (and their effect on outcomes) is the likely cause for heterogeneous surveillance intervals found in our responses.

In addition to MRI, a small proportion of survey respondents also reported the use of metabolic imaging (FDG-PET) for the evaluation of both adults and children with asymptomatic and symptomatic PN. Interestingly, among the various clinical indications included in our survey, whole-body ${ }^{18} \mathrm{~F}-\mathrm{FDG}$ PET/CT was most often obtained in a symptomatic child with known or visible PN (17\%, 5/30). As expected, the utilization of whole-body ${ }^{18} \mathrm{~F}-\mathrm{FDG}$ PET/MRI was less frequent relative to whole-body ${ }^{18} \mathrm{~F}-\mathrm{FDG} \mathrm{PET} / \mathrm{CT}$, probably due to limited single-center experience and lack of availability of hybrid PET/MRI platforms in most clinical centers. ${ }^{18}$ Whereas WB-MRI has been traditionally used for the detection and quantification of internal PN burden, FDG-PET offers high diagnostic accuracy for the detection of MPNST in this patient population using SUV. ${ }^{17,19}$ Similar to FDG-PET, whole-body or regional MRI with DWI enables quantification 
of $\mathrm{ADC}$ values, a marker for cellularity and potentially malignancy. ${ }^{19-21}$ Of note, the majority (86\%) of survey respondents indicated familiarity with quantitative imagingbased markers for malignancy in NF1 such as ADC and SUV. Recent studies ${ }^{19-23}$ suggest that mean or minimum $\mathrm{ADC}$ values derived from DWI may be more useful to distinguish between benign and malignant PNSTs than qualitative features on T1- and T2-weighted images. These findings need to be validated prospectively in a larger patient population. Although DWI may be superior to standard anatomical MRI under certain circumstances, survey respondents more often utilized PET SUVs for planning a targeted biopsy in suspicious PNST, likely due to greater experience with PETderived markers. ${ }^{19}$ Identifying a quantitative imaging biomarker that can differentiate atypical neurofibromas from benign and malignant tumors would have significant clinical value as it would help identify patients at risk of malignant conversion and potentially enable earlier intervention.

Our study has several limitations. Firstly, it is a survey-based instrument rather than an actual measurement of imaging utilization in a clinical practice. The survey does, however, provide insight into practice patterns among clinical experts in NF1. Secondly, the majority of our survey respondents were academic, American neuro-oncologists (90\%) with access to WB-MRI, which introduces a selection bias (potentially reflecting insurance-funded NF1 care practice patterns rather than communal, government, or tax-paid NF1 care practice patterns). This population is not representative of a typical practitioner that evaluates a person with NF1 but does reflect medical practitioners in tertiary, NF1 specialty centers. Furthermore, we did not specify the definition of WB-MRI and there are multiple approaches employed around the globe that may have differences in time required and data generated.

Developing and implementing evidence-based guidelines for imaging utilization in people with NF1 to detect PN and prevent development of morbidity or malignant conversion has the potential to improve outcomes for patients, decrease health care spending, and reduce overall burden to patients, their caregivers, and the medical system. To achieve this, we propose prospective evaluation of the following topics using WB-MRI: (1) natural history of a large cohort of patients with NF1 with PN across multiple age ranges; (2) identification of patients at risk of developing an MPNST from a preexisting $\mathrm{PN}$, based on prospective analysis of MRI and clinical features; and (3) identification of patients most likely to respond to MEK inhibitor therapy, based on MRI and clinical characteristics. In the future, the creation of large, clinically annotated imaging databases may enable the application of machine learning/artificial intelligence techniques to enhance our ability to detect/quantify internal PN, characterize MPNST in the background of $\mathrm{PN}$, and assess treatment response for patients undergoing systemic therapies with greater accuracy and efficiency. In order to build such databases, compare imaging studies across sites, and perform robust clinical trials, it will be important to standardize imaging protocols. Imaging for PNST should include a fluid-sensitive MRI sequence such as STIR sequences to afford optimal visualization of PNSTs. ${ }^{8}$

\section{Acknowledgment}

The authors acknowledge the support of the Children's Tumor Foundation for the REiNS International Collaboration.

\section{Study Funding}

The authors report no targeted funding.

\section{Disclosures}

S. Ahlawat has received research grants from Pfizer, the Department of Defense, and International Skeletal Society. K.I. Ly has received research support from the Neurofibromatosis Therapeutic Acceleration Program. L.M. Fayad has received research grants from the General Electric Radiology Research Academic Fellowship Program and Siemens Medical Systems. M. Fisher, A. Lessing, D. Berg, J.M. Salamon, and V. Mautner report no disclosures. D. Babovic-Vuksanovic reports research support from the Department of Defense and serves as a consultant to Loeb \& Loeb in a patent case for pirfenidone as well as consultant for AstraZeneca. E. Dombi reports no disclosures. G.J. Harris serves as a Scientific Advisor to Fovia Inc. and is a member of IQ Medical Imaging LLC and Novometrics LLC. S. Plotkin serves as advisor for AstraZeneca and has ownership interests in NFlection Therapeutics, Inc. and NF2. J.O. Blakeley has received research support from GlaxoSmithKline, SanofiAventis, and Lily Pharmaceuticals and has consulted for AbbVie. Go to Neurology.org/N for full disclosures.

\section{Publication History}

Received by Neurology October 16, 2020. Accepted in final form April 23, 2021.

Appendix Authors

\begin{tabular}{lll}
\hline Name & Location & Contribution \\
\hline $\begin{array}{l}\text { Shivani } \\
\text { Ahlawat, MD }\end{array}$ & $\begin{array}{l}\text { Johns Hopkins University, } \\
\text { Baltimore, MD }\end{array}$ & $\begin{array}{l}\text { Conceptualization of the } \\
\text { study; interpretation of the } \\
\text { data; drafting the } \\
\text { manuscript }\end{array}$ \\
\hline K. Ina Ly, MD & $\begin{array}{l}\text { Massachusetts General } \\
\text { Hospital, Boston }\end{array}$ & $\begin{array}{l}\text { Conceptualization of the } \\
\text { study; interpretation of the } \\
\text { data; drafting the } \\
\text { manuscript }\end{array}$ \\
\hline $\begin{array}{l}\text { Laura M. } \\
\text { MD }\end{array}$ & $\begin{array}{l}\text { Johns Hopkins University, } \\
\text { Baltimore, MD }\end{array}$ & $\begin{array}{l}\text { Revising the manuscript for } \\
\text { intellectual content }\end{array}$ \\
\hline $\begin{array}{l}\text { Michael J. } \\
\text { Fisher, MD }\end{array}$ & $\begin{array}{l}\text { Children's Hospital of } \\
\text { Philadelphia, PA }\end{array}$ & $\begin{array}{l}\text { Conceptualization of the } \\
\text { study; drafting the } \\
\text { manuscript }\end{array}$ \\
\hline $\begin{array}{l}\text { Andres J. } \\
\text { Lessing, MBA }\end{array}$ & Massachusetts & $\begin{array}{l}\text { Revising the manuscript for } \\
\text { intellectual content }\end{array}$ \\
\hline $\begin{array}{l}\text { Salamon, MD } \\
\text { Dale Berg }\end{array}$ & $\begin{array}{l}\text { Minnesota } \\
\text { Hamburg-Eppendorf, }\end{array}$ & $\begin{array}{l}\text { Revising the manuscript for } \\
\text { intellectual content }\end{array}$ \\
\hline
\end{tabular}


Appendix (continued)

\begin{tabular}{|c|c|c|}
\hline Name & Location & Contribution \\
\hline $\begin{array}{l}\text { Victor-Felix } \\
\text { Mautner, MD }\end{array}$ & $\begin{array}{l}\text { University Medical Center } \\
\text { Hamburg-Eppendorf, } \\
\text { Hamburg, Germany }\end{array}$ & $\begin{array}{l}\text { Revising the manuscript for } \\
\text { intellectual content }\end{array}$ \\
\hline $\begin{array}{l}\text { Dusica } \\
\text { Babovic- } \\
\text { Vuksanovic, } \\
\text { MD }\end{array}$ & Mayo Clinic, Rochester, MN & $\begin{array}{l}\text { Revising the manuscript for } \\
\text { intellectual content }\end{array}$ \\
\hline $\begin{array}{l}\text { Eva Dombi, } \\
\text { MD }\end{array}$ & $\begin{array}{l}\text { Pediatric Oncology Branch, } \\
\text { National Cancer Institute, } \\
\text { Bethesda, MD }\end{array}$ & $\begin{array}{l}\text { Conceptualization of the } \\
\text { study; revising the } \\
\text { manuscript for intellectual } \\
\text { content }\end{array}$ \\
\hline $\begin{array}{l}\text { Gordon } \\
\text { Harris, PhD }\end{array}$ & $\begin{array}{l}\text { Massachusetts General } \\
\text { Hospital, Boston }\end{array}$ & $\begin{array}{l}\text { Conceptualization of the } \\
\text { study; revising the } \\
\text { manuscript for intellectual } \\
\text { content }\end{array}$ \\
\hline $\begin{array}{l}\text { Scott R. } \\
\text { Plotkin, MD, } \\
\text { PhD }\end{array}$ & $\begin{array}{l}\text { Massachusetts General } \\
\text { Hospital, Boston }\end{array}$ & $\begin{array}{l}\text { Conceptualization of the } \\
\text { study; revising the } \\
\text { manuscript for intellectual } \\
\text { content }\end{array}$ \\
\hline $\begin{array}{l}\text { Jaishri } \\
\text { Blakeley, MD }\end{array}$ & $\begin{array}{l}\text { Johns Hopkins University, } \\
\text { Baltimore, MD }\end{array}$ & $\begin{array}{l}\text { Conceptualization of the } \\
\text { study; drafting the } \\
\text { manuscript; revising the } \\
\text { manuscript for intellectual } \\
\text { content }\end{array}$ \\
\hline
\end{tabular}

\section{References}

1. Seminog O, Goldacre M. Risk of benign tumours of nervous system, and of malignant neoplasms, in people with neurofibromatosis: population-based record-linkage study. Br J Cancer. 2012;108(1):193-198.

2. Evans D. Malignant peripheral nerve sheath tumours in neurofibromatosis $1 . \mathrm{J} \mathrm{Med}$ Genet. 2002;39(5):311-314.

3. Mautner V, Asuagbor F, Dombi E, et al. Assessment of benign tumor burden by whole-body MRI in patients with neurofibromatosis 1. Neuro-Oncol. 2008;10(4): 593-598.

4. Leroy KE. Malignant Peripheral Nerve Sheath Tumors Associated with Neurofibromatosis Type 1: A Clinicopathologic and Molecular Study of 17 Patients ( 25 March 2020). Available at: ncbi.nlm.nih.gov/pubmed/11453810

5. Valeyrie-Allanore L, Ismaili N, Bastuji-Garin S, et al. Symptoms associated with malignancy of peripheral nerve sheath tumours: a retrospective study of 69 patients with neurofibromatosis 1. Br J Dermatol. 2005;153(1):79-82.
6. Hersh J. Health supervision for children with neurofibromatosis. Pediatrics. 2008; 121(3):633-642.

7. Valentin T, Le Cesne A, Ray-Coquard I, et al. Management and prognosis of malignant peripheral nerve sheath tumors: the experience of the French Sarcoma Group (GSF-GETO). Eur J Cancer. 2016;56:77-84.

8. Ahlawat S, Fayad L, Khan M, et al. Current whole-body MRI applications in the neurofibromatoses. Neurology. 2016;87(7 suppl 1):S31-S39.

9. Evans D, Salvador H, Chang V, et al. Cancer and central nervous system tumor surveillance in pediatric neurofibromatosis 1. Clin Cancer Res. 2017;23(12):e46-e53.

10. Nguyen R, Jett K, Harris G, Cai W, Friedman J, Mautner V. Benign whole body tumor volume is a risk factor for malignant peripheral nerve sheath tumors in neurofibromatosis type 1. J Neuro-Oncol. 2013;116(2):307-313.

11. Nguyen R, Dombi E, Widemann B, et al. Growth dynamics of plexiform neurofibromas: a retrospective cohort study of 201 patients with neurofibromatosis 1 . Orphanet J Rare Dis. 2012;7(1):75.

12. Ahlawat S, Blakeley J, Langmead S, Belzberg A, Fayad L. Current status and recommendations for imaging in neurofibromatosis type 1, neurofibromatosis type 2, and schwannomatosis. Skeletal Radiol. 2019;49(2):199-219.

13. Gross A, Singh G, Akshintala S, et al. Association of plexiform neurofibroma volume changes and development of clinical morbidities in neurofibromatosis 1. Neuro-Oncology. 2018;20(12):1643-1651.

14. Meany H, Dombi E, Reynolds J, et al. 18-fluorodeoxyglucose-positron emission tomography (FDG-PET) evaluation of nodular lesions in patients with Neurofibromatosis type 1 and plexiform neurofibromas (PN) or malignant peripheral nerve sheath tumors (MPNST). Pediatr Blood Cancer. 2013;60(1):59-64.

15. Miettinen MM, Antonescu CR, Fletcher CDM, et al. Histopathologic evaluation of atypical neurofibromatous tumors and their transformation into malignant peripheral nerve sheath tumor in patients with neurofibromatosis 1: a consensus overview. Hum Pathol. 2017;67:1-10.

16. Dombi E, Baldwin A, Marcus L, et al. Activity of selumetinib in neurofibromatosis type 1-related plexiform neurofibromas. $N$ Engl J Med. 2016;375(26):2550-2560.

17. Plotkin SR, Bredella MA, Cai W, et al. Quantitative assessment of whole-body tumor burden in adult patients with neurofibromatosis. PLoS One. 2012;7(4): e35711.

18. Raad R, Lala S, Allen J, et al. Comparison of hybrid ${ }^{18}$ F-fluorodeoxyglucose positron emission tomography/magnetic resonance imaging and positron emission tomography/computed tomography for evaluation of peripheral nerve sheath tumors in patients with neurofibromatosis type 1. World J Nucl Med.2018; 17(4):241.

19. Brahmi M, Thiesse P, Ranchere D, et al. Diagnostic accuracy of PET/CT-Guided percutaneous biopsies for malignant peripheral nerve sheath tumors in neurofibromatosis type 1 patients. PLoS One. 2015;10(10):e0138386.

20. Uthoff J, De Stefano FA, Panzer K, et al. Radiomic biomarkers informative of cancerous transformation in neurofibromatosis-1 plexiform tumors. J Neuroradiol. 2019; 46(3):179-185.

21. Well L, Salamon J, Kaul MG, et al. Differentiation of peripheral nerve sheath tumors in patients with neurofibromatosis type 1 using diffusion-weighted magnetic resonance imaging. Neuro Oncol. 2019;21(4):508-516.

22. Demehri S, Belzberg A, Blakeley J, Fayad LM. Conventional and functional MR imaging of peripheral nerve sheath tumors: initial experience. AJNR Am J Neuroradiol. 2014;35(8):1615-1620.

23. Ahlawat S, Fayad LM. Imaging cellularity in benign and malignant peripheral nerve sheath tumors: utility of the "target sign" by diffusion weighted imaging. Eur J Radiol. 2018;102:195-201. 


\section{Neurology}

\section{Imaging Evaluation of Plexiform Neurofibromas in Neurofibromatosis Type 1: A Survey-Based Assessment}

Shivani Ahlawat, K. Ina Ly, Laura M. Fayad, et al. Neurology 2021;97;S111-S119 Published Online before print July 6, 2021

DOI 10.1212/WNL.0000000000012437

\section{This information is current as of July 6, 2021}

\section{Updated Information \& Services}

References

Citations

Subspecialty Collections

Permissions \& Licensing

Reprints including high resolution figures, can be found at: http://n.neurology.org/content/97/7_Supplement_1/S111.full

This article cites 22 articles, 4 of which you can access for free at: http://n.neurology.org/content/97/7_Supplement_1/S111.full\#ref-list-1

This article has been cited by 1 HighWire-hosted articles: http://n.neurology.org/content/97/7_Supplement_1/S111.full\#\#otherarti cles

This article, along with others on similar topics, appears in the following collection(s):

Neurofibromatosis

http://n.neurology.org/cgi/collection/neurofibromatosis

Information about reproducing this article in parts (figures,tables) or in its entirety can be found online at:

http://www.neurology.org/about/about_the_journal\#permissions

Information about ordering reprints can be found online:

http://n.neurology.org/subscribers/advertise

Neurology ${ }^{\circledR}$ is the official journal of the American Academy of Neurology. Published continuously since 1951, it is now a weekly with 48 issues per year. Copyright @ 2021 American Academy of Neurology. All rights reserved. Print ISSN: 0028-3878. Online ISSN: 1526-632X.

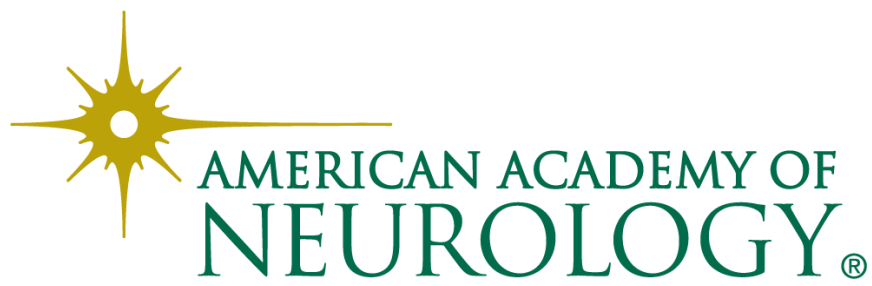

